\title{
西北太平洋表层海水中 $\mathrm{Zn} 、 \mathrm{Cd} 、 \mathrm{~Pb} 、 \mathrm{Cu}$ 的形态分布
}

本文用防吸附物理涂永电极反向极谱研究了西 北太平洋表层海水中 $\mathrm{Zn} 、 \mathrm{Cd} 、 \mathrm{~Pb} 、 \mathrm{Cu}$ 的形态分 布. $\mathrm{Zn}_{\mathrm{n}}$ 的含量范围为, 不稳定态 $3.0-6.9 \mu \mathrm{g} / 1$, 无 机弱结合态 $0.20-4.3 \mu \mathrm{g} / 1$, 无机强结 合 态 2.6$8.3 \mu \mathrm{g} / \mathrm{l}$, 有机 结合态 $0.80-11.4 \mu \mathrm{g} / 1$, 颗粒态 $2.0-14.4 \mu \mathrm{g} / 1$, 总 $\mathrm{Z}_{\mathrm{n}}$ 的范围是 $8.6-34.8 \mu \mathrm{g} / \mathrm{l}$. Cd 的含量范围为, 不稳定态 $0.060-0.19 \mu \mathrm{g} / 1$, 无机弱 结合态 $0.020-0.17 \mu \mathrm{g} / 1$, 无机强结 合态 $0.020-$ $0.19 \mu \mathrm{g} / 1$, 有机结合态 $0.010-0.10 \mu \mathrm{g} / 1$, 颗粒态 $0.050-0.20 \mu \mathrm{g} / 1$, 总 Cd 的范围是 $0.20-0.46 \mu \mathrm{g} / 1$. $\mathrm{Pb}$ 的含量范围, 不稳定态 $0.017-0.046 \mu \mathrm{g} / \mathrm{l}$, 无 机弱结合态 $0.040-0.046 \mu \mathrm{g} / 1$, 无机强结合态 $0.013-0.045 \mu \mathrm{g} / 1$, 有机结合态 $0.0020-0.043 \mu \mathrm{g} /$

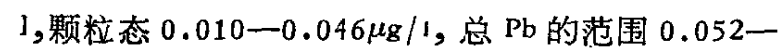
$0.14 \mu \mathrm{g} / 1$. Cu 的含量范围为, 不稳定态 $0.40-0.79$ $\mu \mathrm{g} / \mathrm{l}$, 无机弱结合态 $0.10-0.47 \mu \mathrm{g} / \mathrm{l}$, 无机强结合 态 $0.13-0.59 \mu \mathrm{g} / 1$, 有机结合态 $0.060-0.61 \mu \mathrm{g} / \mathrm{l}$, 颗粒态 $0.21-0.84 \mu \mathrm{g} / 1$, 总 $\mathrm{Cu}$ 的范围 1.1-2.2 $\mu g / 1$.

从分析结果看出，太平洋中部至东海及江口处
表层海水中 $\mathrm{Zn} 、 \mathrm{Cd} 、 \mathrm{Pd} 、 \mathrm{Cu}$ 的不稳定态分布较为 均匀, 与顾宏堪等报道的中国近海海水中几种微量 金属离子的分布研究结果相一致，并进一步证实了 “天然水中痕量金属离子的均匀分布规律”的存在. 无机弱结合态除 $\mathrm{Cd}$ 的分布东海及江口稍 低以外， $\mathrm{Zn} 、 \mathrm{~Pb} 、 \mathrm{Cu}$ 的分布也较均匀. 有机结合态及颗粒态 $\mathrm{Zn} 、 \mathrm{Cd}$ 的浓度分布东海及江口较太平洋中部 表层水 的稍高, 颗粒态 $\mathrm{Cu}$ 的浓度分布东海及江口的增高较 为明显, 这与 Niino 及秦蕴珊等所述鲮浮体高含量 位于长江口附近及大陆沿岸一带相一致. 有机物含 量的多少与悬浮体及沉积物粒径的粗细变化有密切 关系，生物遗畡的软组织及其排泄物等有机组份在 悬浮体及沉积物中主要以有机质形式出现, 多分布 于内陆架细粒悬浮体及沉积物中, 所以江口处水中 有机结合态及颗粒态金属浓度含量较高. 在未污染 的江口天然水中，悬浮体与 $\mathrm{Zn}^{2+}$ 等自由离子之间， 没有明显的平衡转移, 体系不处于热力学平衡状态.

张首临 刘明星 李国基 顾宏堪 (中国科学院海洋研究所，青岛)

\section{中国若干基性岩和伟晶岩锶同位素 地球化学特征的研究}

磷灰石的晶体化学结构稳定, 对 $\mathrm{Rb} 、 \mathrm{Sr}$ 保存性 良好, 抗风化能力强; 基性岩和伟晶岩中磷灰石的含 量往往较高. 因此, 用磷灰石来研究这些岩类的锶 闰位素特征以探讨岩石成因、物质来源及地球化学 过程。

1. 中国某些基性岩的磷灰石富 $\mathrm{Sr}$ 贫 $\mathrm{Rb}$, 放射成 因锶的影响 $<5 \times 10^{-5}-1.9 \times 10^{-4}$; 同一岩体磷灰 石的 $\mathrm{Sr}$ 同位素比值 [简称 $\left({ }^{87} \mathrm{Sr} /{ }^{86} \mathrm{Sr}\right) \mathrm{ap}$ ] 相当均 一. 因此, 基性岩中原生磷灰石的 $\left({ }^{87} \mathrm{Sr} /{ }^{86} \mathrm{Sr}\right)$ ap 比 值可以表征其初始值。

2 中国若干基性岩的 $\left({ }^{87} \mathrm{Sr} /{ }^{86} \mathrm{Sr}\right) \mathrm{ap}$ 比值介于 0.7034-0.7107. 如某些层状辉长岩和某些斜长岩 的 $\left({ }^{87} \mathrm{Sr} /{ }^{86} \mathrm{Sr}\right)$ ap 比值为 $0.7034-0.7047$. 它们 是大型和特大型钒铲磁铁矿的成矿母岩; 某些辉长 岩和橄榄辉长岩体的 $\left.{ }^{87} \mathrm{~S} r /{ }^{86} \mathrm{~S} r\right) \mathrm{ap}$ 比值为 0.7080-0.7107,它们可能来自上地幔富碱金属带,
且在深部经历了一定程度的分异演化.

3.一些基性岩和碱性岩, 空间上伴生, 具有十分 一致的 Sr 同位素和 REE 特征, 属同源岩浆岩。

4. 某些元古代伟晶岩的 $\left({ }^{87} \mathrm{Sr} /{ }^{86} \mathrm{Sr}\right)$ ap 比值低 达 0.7026-0.7033, 其磷灰石高度贫 $\mathrm{Rb}$ 富 Sr, 放 射成因 $\mathrm{Sr}$ 的影响低于 $8 \times 10^{-3}$. 因此, 其 (" $\mathrm{Sr}$ ) ${ }^{86 S r}$ ) ap 比值能表征这类伟晶岩的 $\left({ }^{87} \mathrm{Sr} /{ }^{86} \mathrm{Sr}\right) \mathrm{i}$ 比 值。这类伟晶岩常与基性岩、超基性岩或碱性岩伴 生,其成岩成矿物质主要源于上地幔,与幔源岩装晚 期的分异作用有关. 其显著的特点是其中的磷灰石

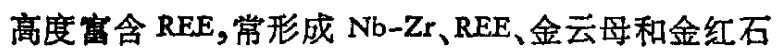
研化。

5 .壳源型伟昆岩的 $\left({ }^{87} \mathrm{Sr} /{ }^{86} \mathrm{Sr}\right)$ ap 比值都大于 0.710 ,其成岩成矿物质主要来自上部地壳. 这类伟 晶岩特别是重熔岩浆分异伟晶岩以富 $\mathrm{Rb}$ 贫 $\mathrm{Sr}$, 明显 高甚至异常高的 $\left(^{87} \mathrm{Sr} /{ }^{86} \mathrm{Sr}\right.$ ) ap 比值 (0.745- 